\title{
Management Thyroid Disease in Pregnancy: Preconception, and the postpartum complications
}

\author{
*R F Gross man 1*, Sami Micheal1 \\ Department of Endocrinology, Diabetics, Israel.
}

*Corresponding Author : R F Gross man, Department of Endocrinology, Canada. Email: grossman.rf@gmail.com

Received date: August 03, 2017;Accepted date : September 09, 2017; Published date: September 27,2017

Citation for this Article : R F Gross man. Management Thyroid Disease in Pregnancy: Preconception, and the postpartum complications. J. Endocrinology and Disorders. Doi: 10.31579/2640-1045/012

Copyright : (C) 2017 RFGross man.This is an open-access article distributed under the terms of the Creative Commons Attribution License, which permits unrestricted use, distribution, and reproduction in any medium, provided the original author and source are credited.

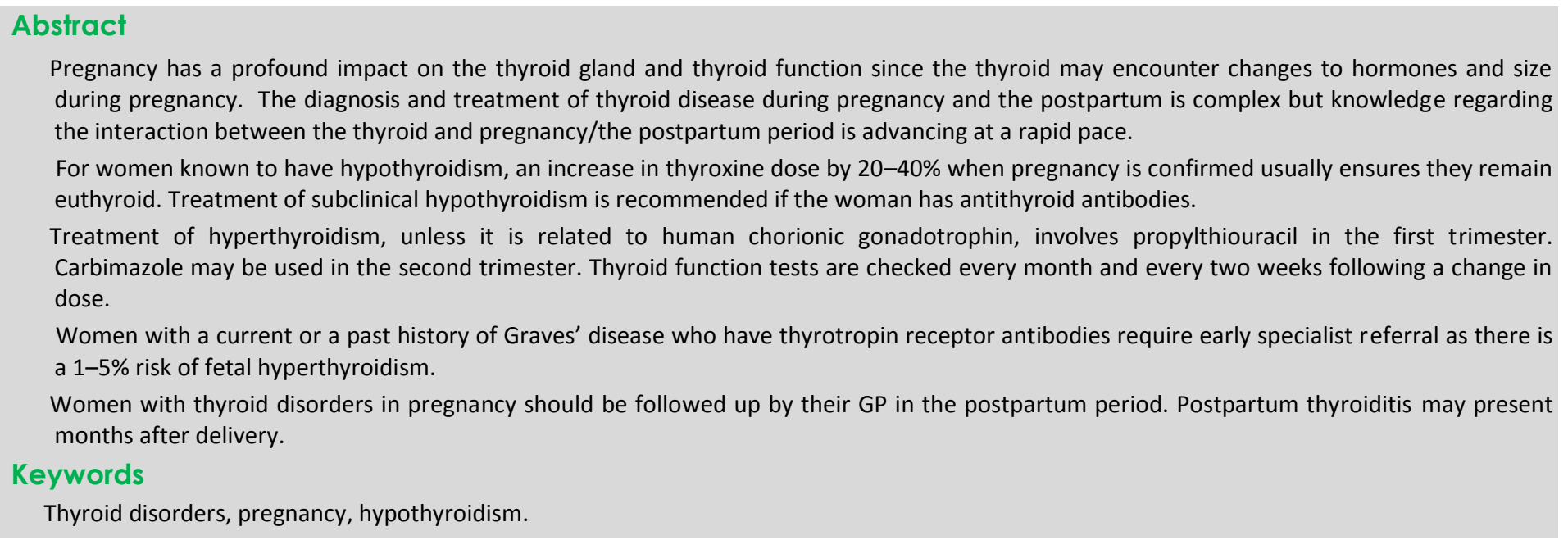

\section{Introduction}

Thyroid disorders are common in pregnancy and related to maternal and fetal complications.

Hyperthyroidism occurs in $0.1-0.4 \%$ of pregnant women. Whereas about $2-3 \%$ of pregnant women are hypothyroid, of whom $0.3-0.5 \%$ have overt hypothyroidism and $2-2.5 \%$ present subclinical hypothyroidism.

At least 5-10\% of women are positive for thyroid antibodies and have an increased risk of developing a certain degree of thyroid insufficiency during pregnancy.

Thyroid function is influenzed by pregnancy and its dysfunction is associated with maternal and fetal morbidity. Moreover the role of subclinical hypothyroidism in the developement of fetal and maternal complications is not univocal. Indeed subclinical hyperthyroidism is not associated with adverse outcomes. Thyroid autoimmunity appears to be associated with an increased risk of miscarriage and preterm delivery.

In this article we aimed to review the possible adverse maternal and fetal outcomes of thyroid during pregnancy and the proper management of these conditions to avoid such complications.

Physiology of maternal and fetal thyroid in pregnancy

During pregnancy the thyroid gland undergoes hyperplasia and increased vascularity. Circulating iodine is reduced and thyroidbinding globulin increases.
The rising concentration of beta-human chorionic gonadotrophin (HCG) in the first trimester can directly stimulate the thyroid stimulating hormone (TSH) receptor as HCG has structural similarities to TSH. This in turn leads to increased free triidothyronine (fT3) and free thyroxine (fT4), suppressing TSH secretion. A serum TSH below $0.1 \mathrm{mIU} / \mathrm{L}$ may be present in $5 \%$ of women by the 11th week of pregnancy.

The TSH subsequently normalises as beta-HCG falls in the second and third trimesters.

In view of these physiological changes, consult gestation-specific TSH concentration ranges when interpreting thyroid function tests. These reference ranges differ from non-pregnant ranges (Table 1).

\section{Table 1}

Normal thyroid stimulating hormone concentrations in pregnancy

\begin{tabular}{|l|l|}
\hline Gestation & Thyroid stimulating hormone (mIU/L) \\
\hline First trimester & $0.1-2.5$ \\
\hline Second trimester & $0.2-3.0$ \\
\hline Third trimester & $0.3-3.0$ \\
\hline
\end{tabular}

Note that individual laboratories may have slightly different pregnancyspecific ranges and it is important to confirm ranges with your local pathologist. 


\section{Women with hypothyroidism}

After conception, an increase in thyroxine as soon as possible is recommended with the goal of normalising the TSH concentration. An easy approach is to increase the total weekly thyroxine dose by an extra two tablets per week or by $20-30 \%$ of the baseline dose when pregnancy is confirmed.

Serum TSH should be monitored every four weeks in the first trimester to ensure the woman is euthyroid, and then six to eight weekly therafter.Thyroid function tests should be rechecked four weeks after any dosage adjustments to ensure euthyroid levels are maintained. Aim to maintain TSH in the range $0.5-2.5 \mathrm{mIU} / \mathrm{L}$.

Failure to achieve a euthyroid state despite appropriate therapy necessitates investigation into causes for a lack of thyroxine uptake. This can result from poor adherence to therapy or impaired absorption. Women should be advised to take their thyroxine on an empty stomach before breakfast. There should be a 4-5 hour gap before taking medicines such as vitamins, calcium and iron tablets as interactions in the gastrointestinal tract can reduce thyroxine absorption.

Following delivery, the thyroxine dose should be reduced to the patient's preconception dose, assuming the woman was euthyroid on that dose. Check thyroid function tests 4-6 weeks after their dose has been reduced postpartum.

\section{Hypothyroidism diagnosed during pregnancy}

A new diagnosis of overt hypothyroidism should warrant immediate thyroxine replacement and further investigation for the presence of thyroid auto-antibodies:

- $\quad$ antithyroid peroxidase antibodies (antiTPO)

- antithyroglobulin antibodies (TgAb)

- thyrotropin receptor antibodies (TRAb) (if there is a history of treated Graves' disease)

\section{Subclinical hypothyroidism}

Subclinical hypothyroidism in pregnancy is associated with an increased risk of recurrent miscarriage, intrauterine growth restriction, preterm birth, low birth weight, perinatal mortality and preeclampsia.Thyroxine may reduce associated risks Recent studies support thyroxine replacement in women with subclinical hypothyroidism undergoing assisted reproduction technologies, to improve pregnancy outcome. The aim of treatment is to achieve a TSH less than $2.5 \mathrm{mIU} / \mathrm{L}$.

The American Thyroid Association in 2017 updated its guidelines for the management of thyroid disease in pregnancy following new research. Thyroxine should be given if there are antithyroid antibodies and the initial TSH is $2.5-4 \mathrm{mIU} / \mathrm{L}$. If the initial TSH is $4 \mathrm{mIU} / \mathrm{L}$ or more, start thyroxine irrespective of antibody status.

If a decision is made to treat subclinical hypothyroidism, the suggested starting dose of thyroxine is 50 micrograms per day. Thyroid function tests are checked within four weeks of starting therapy.

\section{Results}

As the pregnancy advances, dose requirement comes down in most of the cases; one-third of pregnant women can actually stop anti-thyroid medication in the third trimester. A significant percentage of these women need to start after delivery for relapse. Our routine practice is to check the thyroid function two weeks after delivery as opposed to six to eight weeks in cases of hypothyroidism. Beta-blockers, if necessary, can be given for a short duration for controlling symptoms. When thyroidectomy is needed for the control of hyperthyroidism, it should be planned in the second trimester of pregnancy; fortunately, this is very rare, and none of the authors can remember a single case they referred to surgeons for uncontrolled hyperthyroidism in pregnancy.
Breast feeding while on anti-thyroid medication remains a sensitive issue; PTU is the preferred medicine as it is more protein-bound and is secreted least in breast milk. Up to $600 \mathrm{mg}$ a day PTU is considered safe; it is recommended to keep an eye on growth of the baby clinically with biochemical test for thyroid function if suspected for growth problem.

Showing the thyroid function and treatment of a patient with Graves' disease in pregnancy treated by the authors

\begin{tabular}{|c|c|c|c|c|c|c|c|c|c|c|c|c|}
\hline & $\begin{array}{l}\text { Six months } \\
\text { betore } \\
\text { conception }\end{array}$ & $\begin{array}{l}\text { Three } \\
\text { months } \\
\text { betore }\end{array}$ & $6 \mathrm{WkS}^{+}$ & 8Wks 1 & 12 WKs & 17 Wks & 22 Wks & 27 Wks & 30 WKS & 36 Wks & $\begin{array}{c}2 W \mathrm{WS} \\
\mathrm{pP}\end{array}$ & $\begin{array}{l}\text { 6WKS } \\
\text { Pp }\end{array}$ \\
\hline TSH & $<0.05$ & $<0.05$ & $<0.05$ & 0.4 & 0.4 & 1.1 & 2.3 & 1.7 & 2.1 & 2.9 & 0.05 & 0.05 \\
\hline freet3 & 7.8 & 5.1 & 4.8 & 4.2 & 3.5 & 2.7 & 3.5 & 3.9 & 2.1 & 2.7 & 4.9 & 5.0 \\
\hline Feet T4 & 38 & 27.1 & 26.9 & 27.6 & 10 & 15 & 18 & 16 & 17 & 19 & 28 & 31 \\
\hline PTU me/ (day & $x$ & $x$ & 100 & 200 & 200 & 150 & 100 & 50 & $x$ & $x$ & 100 & 200 \\
\hline NMZm/d & 40 & 30 & stopped & $x$ & $x$ & $x$ & $x$ & $x$ & $x$ & $x$ & $x$ & $x$ \\
\hline
\end{tabular}

Nomal value and units re se same as table l, 'seen frist by us.

Gestational hyperthyroidism or gestational thyrotoxicosis is used when there are symptoms of hyperthyroidism due to the high levels of HCG, which causes thyroid hyperfunction. This condition needs to be differentiated from Graves' disease, as most of the symptoms are similar to those in pregnancy. Up to $15 \%$ of normal pregnancy TSH can be suppressed due to hCG effect; they do not require extra treatment; careful observation is good enough. There is another entity in pregnancy called transient gestational thyroticosis, where free thyroid hormone can be increased, and they require a short course of anti-thyroid medication. Gestational thyrotoxicosis is usually transient and recovers over a period of few weeks. This is essentially a retrospective diagnosis.

\section{Management}

The goal of treatment is to keep the patient euthyroid, using the lowest possible dose of antithyroid drugs necessary to maintain FT4 levels in the upper one-third of the normal non pregnant range or just above the normal range excessive doses of ATDs, indeed, may affect fetal thyroid function, with the development of hypothyroidism and/or goiter

The dose should be adjusted every 2-4 weeks and the presence of detectable TSH is an indication to decrease ATD dose

The treatment of choise is propylthiouracil (PTU), but methimazole (MMI) is also an alternative, both are considered compatible with breastfeeding. PTU is given in a dose of $100-450 \mathrm{mg} /$ day. It may be necessary 2-4 weeks from the start of treatment to see a clinical change. MMI can be prescribed at 10-20 mg/day. Beta blockers may be, also, used to control the adrenergic symptoms of thyrotoxicosis. In addition, beta blockers block the peripheral conversion of T4 to T3. Propranolol in a dose of $10-40 \mathrm{mg}$ every $4-6 \mathrm{~h}$ or atenolol $25-50 \mathrm{mg}$ daily, are recommended. In acute cases, intravenous esmolol (up to 200 $\propto \mathrm{g} / \mathrm{kg} /$ minute) may be used to maintain a heart rate of less than 90 beats/min. Thyroidectomy is reserved for patients requiring high doses of medication or in the rare case of allergies to ATD.

The use of iodine therapy in addition to anti-thyroid medications has fallen into disuse due to higher rates of neonatal goiter and hypothyroidism. Radioactive iodine therapy is contraindicated in pregnancy and lactation. It is recommended to continue medications throughout the postpartum period.

\section{Conclusion}

It is well documented that thyroid disorders are associated with maternal and fetal complications during gestation and sequelea after delivery.

Despite the correlation between thyroid function during pregnancy and maternal and fetal outcomes is a widely discussed topic, it remains to clarify several points. While ADT therapy does not appear to be relevant in patients with subclinical hyperthyroidism, in cases of overt hyperthyroidism it plays a key role. 
In pregnant women with newly diagnose of overt hypothyroidism it is strongly recommended to begin substitutive treatment with LT4 as soon as possible, that should be considered in case of subclinical hypothyroidism; hypothyroid women already being treated by LT4 require an increase of dosage by $30-50 \%$ at the start of pregnancy. In this review we tried to evaluate possible strategies to prevent and to apply appropriate management to avoid an unfavorable outcome for both mother and offspring.

\section{References}

1. Negro R, Mestman JH. Thyroid disease in pregnancy. Best practice \& research. Clinical endocrinology \& metabolism. 2011 Dec;25(6):927-43.

2. Krassas GE, Poppe K, Glinoer D. Thyroid function and human reproductive health. Endocrine Reviews. 2010;31:702-755.

3. El Baba KA, Azar ST. Thyroid dysfunction in pregnancy. International journal of general medicine. 2012;5:227-30. Epub 2012 Mar 6.

4. Gaberšček S, Zaletel K. Thyroid physiology and autoimmunity in pregnancy and after delivery. Expert review of clinical immunology. 2011 Sep;7(5):697-706. quiz 707.

5. Soldin OP, Tractenberg RE, Hollowell JG, et al. Trimesterspecific changes in maternal thyroid hormone, thyrotropin, and thyroglobulin concentrations during gestation: trends and associations across trimesters in iodine sufficiency. Thyroid. 2004;14:1084-1090.

6. Negro R. Significance and management of low TSH in pregnancy. In: Lazarus J, Pirags V, Butz S, editors. The thyroid and reproduction. New York: Georg Thieme Verlag; 2009. pp. 84-95.

7. Casey B, Leveno K. Thyroid disease in pregnancy. Obstet Gynecol. 2006;108(5):1283-1292.

8. Skjoldebrand L, Brundin J, Carlstrom A, Pettersson T. Thyroid associated components in serum during normal pregnancy. Acta Endocrinol. 1982;100(4):504-511.

9. Kurtz A, Dwyer K, Ekins R. Serum free thyroxine in pregnancy. Br Med J. 1979;2(6189):550-551.

10. Boss AM, Kingstone D. Further observations on serum free thyroxine concentrations during pregnancy. Br Med J (Clin Res Ed) $1981 ; 283: 584$.

11. Hopton MR, Ashwell K, Scott IV, Harrop JS. Serum free thyroxine concentration and free thyroid hormone indices in normal pregnancy. Clin Endocrinol. 1983;18:431-437.

12. Glinoer D. The regulation of thyroid function in pregnancy: pathways of endocrine adaptation from physiology to pathology. Endocr Rev. 1997;18(3):404-433.

13. de Escobar GM, Obregón MJ, del Rey FE. Maternal thyroid hormones early in pregnancy and fetal brain development. Best Pract Res Clin Endocrinol Metab. 2004;18:225-248.

14. Kilby MD. Thyroid hormones and fetal brain development. Clin Endocrinol. 2003;59:280-281.

15. Stricker R, Echenard M, Eberhart R, et al. Evaluation of maternal thyroid function during pregnancy: the importance of using gestational age-specific reference intervals. European Journal of Endocrinology. 2007;157:509-514.

16. Haddow JE, Knight GJ, Palomaki GE, et al. The reference range and within-person variability of thyroid stimulating hormone during the first and second trimesters of pregnancy. Journal of Medical Screening. 2004;11:170-174.

17. Kahric-Janicic N, Soldin SJ, Soldin OP, et al. Tandem mass spectrometry improves the accuracy of free thyroxine measurements during pregnancy. Thyroid. 2007;17:303-311.

18. Soldin OP, Hilakivi-Clarke L, Weiderpass E, et al. Trimesterspecific reference intervals for thyroxine and triiodothyronine in pregnancy in iodine-sufficient women using isotope dilution tandem mass spectrometry and immunoassays. Clinica Chimica Acta. 2004;349:181-189.
19. Allan WC, Haddow JE, Palomaki GE, et al. Maternal thyroid deficiency and pregnancy complications: implications for population screening. J Med Screen. 2000;7:127-130.

20. Vaidya B, Anthony S, Bilous M, et al. Detection of thyroid dysfunction in early pregnancy: universal screening or targeted highrisk case finding? Journal of Clinical Endocrinology and Metabolism. 2007;92:203-207.

21. Mitchell ML, Klein RZ, Sargent JD, et al. Iodine sufficiency and measurements of thyroid function in maternal hypothyroidism. Clinical Endocrinology (Oxford) 2003;58:612-616.

22. Casey BM, Dashe JS, Wells CE, et al. Subclinical hypothyroidism and pregnancy outcomes. Obstetrics \& Gynecology. 2005;105:239245

23. Haddow JE, Palomaki GE, Allan WC, et al. Maternal thyroid deficiency during pregnancy and subsequent neuropsychological development of the child. The New England Journal of Medicine. 1999;341:549-555.

24. Glinoer D, Fernandez-Soto ML, Bourdoux P, et al. Pregnancy in patients with mild thyroid abnormalities: maternal and neonatal repercussions. J Clin Endocrinol Metab. 1991;73:421-427.

25. Glinoer D, Riahi M, Grun JP, Kinthaert J. Risk of subclinical hypothyroidism in pregnant women with asymptomatic autoimmune thyroid disorders. J Clin Endocrinol Metab. 1994;79:197-204.

26. Abalovich M, Amino N, Barbour LA, et al. Management of thyroid dysfunction during pregnancy and postpartum: an Endocrine Society Clinical Practice Guideline. J Clin Endocrinol Metab. 2007;92(8 Suppl):S1-S47.

27. Krassas GE, Poppe K, Glinoer D. Thyroid function and human reproductive health. Endocrine Reviews. 2010;31:702-755.

28. Abalovich M, Gutierrez S, Alcaraz G, et al. Overt and subclinical hypothyroidism complicating pregnancy. Thyroid. 2002;12:63-68.

29. Tan TO, Cheng YW, Caughey AB. Are women who are treated for hypothyroidism at risk for pregnancy complications? American Journal of Obstetrics and Gynecology. 2006;194:e1-e3.

30. Negro R, Schwartz A, Gismondi R, et al. Universal screening versus case finding for detection and treatment of thyroid hormonal dysfunction during pregnancy. Journal of Clinical Endocrinology and Metabolism. 2010;95:1699-1707.

31. Abalovich M, Amino N, Barbour LA, et al. Management of thyroid dysfunction during pregnancy and postpartum: an endocrine society clinical practice guideline. Journal of Clinical Endocrinology and Metabolism. 2007;92:S1-S47.

32. Yassa L, Marqusee E, Fawcett R, et al. Thyroid hormone early adjustment in pregnancy (the THERAPY) trial. Journal of Clinical Endocrinology and Metabolism. 2010;95:3234-3241.

33. Alexander EK, Marqusee E, Lawrence J, et al. Timing and magnitude of increases in levothyroxine requirements during pregnancy in women with hypothyroidism. The New England Journal of Medicine. 2004;351:241-249.

34. Caixàs A, Albareda M, García-Patterson A, et al. Postpartum thyroiditis in women with hypothyroidism antedating pregnancy? Journal of Clinical Endocrinology and Metabolism. 1999;84:40004005.

35. Vaidya B, Anthony S, Bilous $\mathrm{M}$, et al. Detection of thyroid dysfunction in early pregnancy: universal screening or targeted highrisk case finding? Journal of Clinical Endocrinology and Metabolism. 2007;92:203-207.

36. Benhadi N, Wiersinga WM, Reitsma JB, et al. Higher maternal TSH levels in pregnancy are associated with increased risk for miscarriage, fetal or neonatal death. European Journal of Endocrinology. 2009;160:985-991.

37. Cleary-Goldman J, Malone FD, Lambert-Messerlian G, et al. Maternal thyroid hypofunction and pregnancy outcome. Obstetrics \& Gynecology. 2008;112:85-92.

38. Männistö T, Vääräsmäki $\mathrm{M}$, Pouta $\mathrm{A}$, et al. Perinatal outcome of children born to mothers with thyroid dysfunction or antibodies: a prospective population-based cohort study. Journal of Clinical Endocrinology and Metabolism. 2009;94:772-779. 
39. Lazarus JH, Bestwick JP, Channon S, et al. Antenatal thyroid screening and childhood cognitive function. The New England Journal of Medicine. 2012 Feb 9;366(6):493-501.

40. Stagnaro-Green A, Roman SH, Cobin RH, et al. Detection of atrisk pregnancy by means of highly sensitive assays for thyroid autoantibodies. Journal of the American Medical Association. 1990;264:1422-1425.

41. Thangaratinam S, Tan A, Knox E, et al. Thyroid autoantibodies are strongly associated with miscarriage and preterm birth:a meta-analysis of evidence. British Medical Journal. 2011;342:d2616.

42. IIjima T, Tada H, Hidaka Y, et al. Effects of autoantibodies on the course of pregnancy and fetal growth. Obstetrics \& Gynecology. 1997;90:364-369.

43. Ghafoor F, Mansoor M, Malik T, et al. Role of thyroid peroxidase antibodies in the outcome of pregnancy. Journal of College of Physicians and Surgeons Pakistan. 2006;16:468-471.

44. Haddow JE, Cleary-Goldman J, McClain MR, et al. First- and Second-Trimester Risk of Aneuploidy (FaSTER) Research Consortium. Thyroperoxidase and thyroglobulin antibodies in early pregnancy and preterm delivery. Obstetrics \& Gynecology. 2010;116:58-62.

45. Negro R. Thyroid autoimmunity and pre-term delivery: brief review and meta-analysis. Journal of Endocrinological Investigation. 2011;34:155-158.

46. Negro R, Formoso G, Mangieri T, et al. Levothyroxine treatment in euthyroid pregnant women with autoimmune thyroid disease: effects on obstetrical complications. Journal of Clinical Endocrinology and Metabolism. 2006;91:2587-2591.

47. Kiprov DD, Natchigall RD, Weaver RC, et al. The use of intravenousimmunoglobulin in recurrent pregnancy loss associated with combined alloimmune and autoimmune abnormalities. American Journal of Reproductive Immunology. 1996;36:228-234.

48. Stricker RB, Steinleitner A, Bookoff CN, et al. Successful treatment of immunologic abortion with low-dose intravenous immunoglobulin. Fertility and Sterility. 2000;73:536-540.

49. Vaquero E, Lazzarin N, De Carolis C. Mild thyroid abnormalities and recurrent spontaneous abortion: diagnostic and therapeutical approach. American Journal of Reproductive Immunology. 2000;43:204-208.

50. Weetman A. Graves' disease. N Engl J Med. 2000;343:12361248.

51. Patil-Sisodia K, Mestman JH. Graves hyperthyroidism and pregnancy: a clinical update. Endocrine Practice. 2010;16:118129.

52. Chan GW, Mandel SL. Therapy insight: management of Graves' disease during pregnancy. Nature Clinical Practice. 2007;3:470478

53. Marx H, Amin P, Lazarus JH. Hyperthyroidism and pregnancy. British Medical Journal. 2008;336:663-667.

54. Tagami $\mathrm{T}$, Hagiwara $\mathrm{H}$, Kimura $\mathrm{T}$, et al. The incidence of gestational hyperthyroidism and postpartum thyroiditis in treated patients with Graves' disease. Thyroid. 2007;17:767-772.
55. Rotondi M, Cappelli C, Pirali B, et al. The effect of pregnancy on subsequent relapse from Graves' disease after a successful course of antithyroid drug therapy. Journal of Clinical Endocrinology and Metabolism. 2008;93:3985-3988.

56. Lee RH, Spencer CA, Mestman JH, et al. Free T4 immunoassays are flawed during pregnancy. American Journal of Obstetrics and Gynecology. 2009;200:260-267.

57. Peleg D, Cada S, Peleg A, et al. The relationship between maternal serum Thyroid-stimulating immunoglobulin and fetal and neonatal thyrotoxicosis. Obstetrics \& Gynecology. 2002;99:1040-1043.

58. Polak M, Le Gac I, Vuillard E, et al. Fetal and neonatal thyroid function in relation to maternal Graves' disease. Best Practice \& Research Clinical Endocrinology \& Metabolism. 2004;18:289-302.

59. Glinoer D, Spencer CA. Serum TSH determinations in pregnancy: how, when and why? Nature Reviews Endocrinology. 2010;6:526529.

60. Tan JY, Loh KC, Yeo GS, et al. Transient hyperthyroidism of hyperemesis gravidarum. British Journal of Obstetrics and Gynaecology. 2002;109:683-688.

61. Higuchi R, Minami S, Yagi S, et al. Gestational thyrotoxicosis during a triplet pregnancy. Journal of Obstetrics and Gynecology. 2008;28:444-445.

62. Momotani N, Noh J, Oyangi H, et al. Antithyroid drug therapy for Graves' disease during pregnancy: optimal regimen for fetal thyroid status. The New England Journal of Medicine. 1986;315:24-28.

63. Burrow GN. Neonatal goiter after maternal propylthiouracil therapy. Journal of Clinical Endocrinology and Metabolism. 1965;25:403408.

64. Cheron RG, Kaplan MM, Larsen PR, et al. Neonatal thyroid function after propylthiouracil therapy for maternal Graves' disease. The New England Journal of Medicine. 1981;304:525-528.

65. Millar LK, Wing DA, Leung AS, et al. Low birth weight and preeclampsia in pregnancies complicated by hyperthyroidism. Obstetrics \& Gynecology. 1994;84:946-949.

66. Bruner J, Landon MB, Gabbe SG. Diabetes mellitus and Graves' disease in pregnancy complicated by maternal allergies to antithyroid medication. Obstetrics \& Gynecology. 1988;72:443-445.

67. Luton D, Le Gac I, Vuillard E, et al. Management of Graves' disease during pregnancy: the key role of fetal thyroid gland monitoring. J Clin Endocrinol Metab. 2005;90:6093.

68. Rivkees SA, Szarfman A. Dissimilar hepatotoxicity profiles of propylthiouracil and methimazole in children. Journal of Clinical Endocrinology and Metabolism. 2010;95:3260-3267.

69. Bahn RS, Burch HS, Cooper DS, et al. The role of propylthiouracil in the management of Graves' disease in adults: report of a meeting jointly sponsored by the American Thyroid Association and the Food and Drug Administration. Thyroid. 2009;19:673-674. 